\title{
Assessing the Impact of Volcanic Eruptions on Climate Extremes Using CMIP5 Models $\mathscr{a}$
}

\author{
SEUNGMOK PAIK AND SEUNG-Ki MiN \\ Division of Environmental Science and Engineering, Pohang University of Science and Technology, Pohang, Gyeongbuk, South Korea
}

(Manuscript received 29 September 2017, in final form 14 February 2018)

\begin{abstract}
This study analyzes extreme temperature and precipitation responses over the global land to five explosive tropical volcanic eruptions that occurred since the 1880s, using CMIP5 multimodel simulations. Changes in annual extreme indices during posteruption years are examined using a composite analysis. First, a robust global decrease in extreme temperature is found, which is stronger than the internal variability ranges (estimated from random bootstrap sampling). Intermodel correlation analysis shows a close relationship between annual extreme and mean temperature responses to volcanic forcing, indicating a similar mechanism at work. The cooling responses exhibit strong intermodel correlation with a decrease in surface humidity, consistent with the Clausius-Clapeyron relation. Second, extreme and mean precipitation reductions are observed during posteruption years, especially in Northern and Southern Hemisphere summer monsoon regions, with good intermodel agreement. The precipitation decreases are also larger than the internal variability ranges and are dominated by the monsoon regions. Moisture budget analysis further reveals that most of the precipitation decrease over the monsoon regions is explained by evaporation decrease, as well as dynamic and thermodynamic contributions. Interestingly, the dynamic effect is found to have a large influence on intermodel spread in precipitation responses, with high intermodel correlation with mean and extreme precipitation changes. These model-based results are largely supported by an observational analysis based on the Hadley Centre Global Climate Extremes Index 2 (HadEX2) dataset for the recent three volcanic eruptions. Our results demonstrate that temperature and precipitation extremes significantly respond to volcanic eruptions, largely resembling mean climate responses, which have important implications for geoengineering based on solar radiation management.
\end{abstract}

\section{Introduction}

Explosive low-latitude volcanic eruptions emit sulfur dioxide gas to the stratosphere, which is oxidized to sulfate aerosols on a time scale of weeks and is spread out globally. The aerosols usually remain with an $e$-folding lifetime of approximately $1 \mathrm{yr}$ in the stratosphere (Barnes and Hofmann 1997). In the stratosphere, the aerosols scatter incoming solar radiation, reducing energy inflow at the surface. This induces global surface and tropospheric cooling, lasting a few years (Robock and Mao 1995). A global reduction in surface moisture occurs after eruptions, which is significantly related to the temperature decrease (Paik and Min 2017). The stratospheric sulfate aerosols also absorb near-infrared radiation and outgoing terrestrial radiation, which

Supplemental information related to this paper is available at the Journals Online website: https://doi.org/10.1175/JCLI-D-17-0651.s1.

Corresponding author: Seung-Ki Min, skmin@postech.ac.kr causes warming in the tropical lower stratosphere (Wielicki et al. 2002). This causes a positive North Atlantic Oscillation (NAO)-like response in the boreal winter following eruptions because of an enhanced poleto-equator temperature gradient (Robock and Mao 1992). This circulation change in turn induces warmer surface conditions over the Northern Hemisphere (NH) continents, precipitation increases over northern Europe, and drier conditions over southern Europe (Fischer et al. 2007; Wegmann et al. 2014).

Previous studies revealed that CMIP5 models reasonably reproduce the observed responses of surface cooling and stratospheric warming to volcanic forcing (Driscoll et al. 2012; Paik and Min 2017). Contrarily, CMIP5 models can hardly reproduce dynamical responses over the $\mathrm{NH}$ in boreal winter, because of the models' underestimation of the observed NAO response (Driscoll et al. 2012). However, recent studies found that models' dynamic responses can be identified during the first winter after eruptions when considering the strong volcanoes only (Bittner et al. 2016; Zambri and Robock 2016). 
Several observation studies reported precipitation decreases following volcanic eruptions in global terrestrial regions (Gillett et al. 2004; Trenberth and Dai 2007). Joseph and Zeng (2011) suggested that the monsoon circulation weakening resulting from reduced land-sea thermal contrast during boreal and austral summer is responsible for the precipitation reduction over the tropics. Using the CMIP5 multimodel ensemble, Paik and Min (2017) confirmed that annual global land precipitation decrease is significantly linked to the monsoon circulation weakening. Using observations and HadCM3 model simulations, Iles et al. (2013) showed that climatologically wet regions experience drying and dry regions become wetter in the tropics after eruptions. They further found that the HadCM3 model underestimates global precipitation response in boreal winter, which originates from the wet tropical regions. Iles and Hegerl (2014) confirmed the main feature of precipitation reductions using CMIP5 models. On the other hand, Liu et al. (2016) found that $\mathrm{NH}$ eruptions are efficient in reducing the $\mathrm{NH}$ precipitation while Southern Hemisphere (SH) eruptions are efficient in reducing $\mathrm{SH}$ monsoon precipitation. They showed that the latitudinal dependence of precipitation response occurs through strong divergence anomalies associated with the low-level cross-equatorial flows, which are driven by the enhanced hemispheric thermal contrast and moisture reduction. In short, tropical volcanic eruptions tend to induce a large precipitation decrease in summer monsoon (wet) regions mainly through the moisture reduction and the monsoon circulation weakening.

Although the impact of explosive tropical volcanic eruptions on global temperature and precipitation has been widely studied, extreme climate responses have not been investigated, to our knowledge. Since weather and climate extremes exert devastating impacts on human society, the economy, and the ecosystem, understanding variabilities and changes in climate extremes is critical to more-reliable predictions of their changes and associated impacts (IPCC 2012). In this study, extreme climate responses to volcanic eruptions over the global land are analyzed using CMIP5 models. In particular, we investigate the responses of extreme temperature and precipitation indices to five explosive volcanic eruptions since the 1880 s and compare the extreme responses with mean climate responses in order to understand the physical mechanisms. Furthermore, we conduct a moisture budget analysis to explore the contribution of evaporation and dynamic and thermodynamic factors to the hydrological responses. We also examine the observed extreme responses to the recent three volcanoes to evaluate the CMIP5-based results.
TABLE 1. List of CMIP5 model simulations used in this study. Only ensemble member $\mathrm{r} 1 \mathrm{i} 1 \mathrm{p} 1$ is used for each model. (Expansions of acronyms are available online at http://www.ametsoc.org/ PubsAcronymList.)

\begin{tabular}{lcc}
\hline \multirow{2}{*}{\multicolumn{1}{c}{ Models }} & \multicolumn{2}{c}{ Experiment } \\
\cline { 2 - 3 } & ALL & $\mathrm{NAT}$ \\
\hline BCC_CSM1.1 & $\mathrm{X}$ & $\mathrm{X}$ \\
CanESM2 & $\mathrm{X}$ & $\mathrm{X}$ \\
CCSM4 & $\mathrm{X}$ & $\mathrm{X}$ \\
CESM1(FASTCHEM) & $\mathrm{X}$ & \\
CNRM-CM5 & $\mathrm{X}$ & $\mathrm{X}$ \\
CSIRO Mk3.6.0 & $\mathrm{X}$ & $\mathrm{X}$ \\
GFDL CM3 & $\mathrm{X}$ & $\mathrm{X}$ \\
GFDL-ESM2G & $\mathrm{X}$ & \\
GFDL-ESM2M & $\mathrm{X}$ & $\mathrm{X}$ \\
IPSL-CM5A-LR & $\mathrm{X}$ & $\mathrm{X}$ \\
IPSL-CM5A-MR & $\mathrm{X}$ & $\mathrm{X}$ \\
IPSL-CM5B-LR & $\mathrm{X}$ & \\
MIROC5 & $\mathrm{X}$ & $\mathrm{X}$ \\
MIROC-ESM & $\mathrm{X}$ & $\mathrm{X}$ \\
MIROC-ESM-CHEM & $\mathrm{X}$ & $\mathrm{X}$ \\
MRI-CGCM3 & $\mathrm{X}$ & $\mathrm{X}$ \\
NorEMS1-M & $\mathrm{X}$ & 13 models \\
Total & 17 models
\end{tabular}

Section 2 describes the CMIP5 model simulations and observations. In section 3 , the analysis methods are explained. The results are provided in section 4 , including analyses of extreme and mean climate responses, intermodel correlation, moisture budget, and the observational analysis. Conclusions and discussions are given in section 5 .

\section{Data}

Experiments using the multimodel datasets from phase 5 of the Coupled Model Intercomparison Project (CMIP5; Taylor et al. 2012) are used to assess the impacts of explosive tropical volcanic eruptions on climate extremes. We use historical (ALL) model simulations, which were integrated with both anthropogenic and natural external forcing. We also use the historicalNat (NAT) experiment, which includes natural (solar and volcanic activities) forcing only, to better identify naturally driven volcanic influences by comparison with ALL results. For each experiment, a single ensemble member (r1i1p1) is used from each model, which provides all variables analyzed in this study. A total of 17 and 13 models are used for the ALL and NAT experiments, respectively (Table 1 ).

As observations, we use the extreme temperature and precipitation indices from the Hadley Centre Global Climate Extremes Index 2 (HadEX2) datasets (Donat et al. 2013), which have a horizontal resolution of $3.75^{\circ} \times 2.5^{\circ}$ and are available from 1901 to 2010 . To 
TABLE 2. Climate extreme indices used in this study, recommended by the ETCCDI.

\begin{tabular}{ll}
\hline \multicolumn{1}{c}{ Index } & \\
\hline TXx $(\mathrm{K})$ & Monthly max value of daily max temperature. \\
TNn $(\mathrm{K})$ & Monthly min value of daily min temperature. \\
Rx5day (mm) & Monthly max consecutive 5-day precipitation. \\
R95p (mm) & Annual total precipitation when wet day precipitation $\left(\geq 1 \mathrm{~mm} \mathrm{day}^{-1}\right)$ exceeds the 95th percentile of 1961-90. \\
SDII $\left(\mathrm{mm} \mathrm{day}^{-1}\right)$ & Daily precipitation amount on wet days $\left(\geq 1 \mathrm{~mm} \mathrm{day}^{-1}\right)$ in a year. \\
\hline
\end{tabular}

consider different space-time data availability and obtain consistent and reliable responses, we confine our analysis to grids where the observation records exist for at least $70 \%$ of the whole $44-y r$ analysis period (19572000; see below).

\section{Methods}

\section{a. Climate extreme indices}

We use five indices of temperature and precipitation extremes as defined by the Expert Team on Climate Change Detection and Indices (ETCCDI). For extreme temperature, we analyze annual warmest day (TXx) and coldest night (TNn) temperature indices (Table 2). For extreme precipitation, a maximum 5-day consecutive precipitation amount ( $\mathrm{Rx} 5$ day), annual total precipitation on very wet days (R95p), and daily precipitation amount on wet days (SDII) are analyzed (Table 2). Annual extreme responses to each volcanic eruption are obtained by taking the annual maximum (TXx and Rx5day) or minimum (TNn) of monthly indices that are anomalies relative to the 1961-90 mean. Here, months are considered after three complete months following volcanic eruptions (see below). Also, we analyze the annual-mean surface air temperature, specific humidity, and precipitation responses to compare them with the responses of the climate extreme indices. For Rx5day and mean precipitation, seasonal responses are investigated as well to examine summer monsoon responses (note that annual indices of R95P and SDII are not relevant for seasonal analysis). Following Iles et al. (2013) and Iles and Hegerl (2014), we define two half-year seasons as the boreal warm season [May-October (MJJASO)] and the austral warm season [November-April (NDJFMA)].

\section{b. Epoch analysis}

The explosive tropical eruptions are appropriate for studying the global impacts on climate. We analyze the five largest explosive tropical volcanic eruptions since the 1880 s as simulated by the CMIP5 models (Table 3 ). For the observed analysis using the HadEX2 data, three recent volcanic eruptions (Mount Agung, El Chichón, and Mount Pinatubo) are analyzed because HadEX2 has relatively few records during the early twentieth century. Following previous studies, epoch analysis is used to minimize the influence of natural internal variabilities and to examine general impacts of volcanic eruptions on climate (e.g., Iles and Hegerl 2014; Paik and Min 2017). Although each volcanic eruption has different intensity and timing as described in Table 3 , they are quite similar in terms of climate forcing, inducing global-scale cooling and drying (Joseph and Zeng 2011; Iles and Hegerl 2014). The climate responses are calculated as changes relative to preeruption 5-yr means also following previous studies (Fischer et al. 2007; Iles and Hegerl 2014; Paik and Min 2017). Changes from year -4 to year +7 are analyzed, where "year +1 " is defined as the 12-month period after three complete months have passed since the volcano erupted (Table 3 ). The use of up to year +7 is to consider long-lasting responses associated with recoveries after eruptions (see below). In the analysis of seasonal responses, the first year of each season is defined as the season that commenced after the volcano erupted, following Iles et al. (2013) and Iles and Hegerl (2014). For example, for Mount Pinatubo, which erupted in June 1991, year +1 for NDJFMA would be 1992 (November 1991-April 1992) and year +1 for MJJASO would also be 1992. Furthermore, year +1 for annual indices of R95p and SDII is defined as the year that contains more than six months within the 12-month period after three complete months after eruption.

To identify the robustness of volcanic influences on climate, the significance of the climate responses is assessed using a random bootstrap sampling strategy, following Liu et al. (2016) and Barnes et al. (2016). In each model, the responses of the mean or extreme climate within years from -4 to +7 of each eruption are randomly selected and arrayed as a pseudo model simulation data. Using this data, changes relative to preeruption 5-yr means are calculated and composited for five volcanoes. This is repeated for each model and then we obtain the multimodel mean. We repeat this calculation 1000 times and estimate the 1st-99th-percentile ranges, which are used as the significance threshold for assessing the actual model responses. Similarly, for the observations, the climate responses are randomly selected and arrayed 
TABLE 3. Information of major low-latitude volcanic eruptions since the 1880 s analyzed in this study.

\begin{tabular}{|c|c|c|c|c|c|c|}
\hline Volcano & Eruption date $^{\mathrm{a}}$ & $\begin{array}{c}\text { Start month of } \\
\text { year }+1 \text { for annual } \\
\text { extreme and mean }\end{array}$ & $\begin{array}{c}\text { MJJASO } \\
\text { year }+1\end{array}$ & $\begin{array}{l}\text { NDJFMA } \\
\text { year }+1^{\text {b }}\end{array}$ & $\begin{array}{c}\text { Year }+1 \text { for } \\
\text { annual indices }\end{array}$ & $\begin{array}{l}\text { Lower stratosphere } \\
\mathrm{SO}_{2} \text { mass }(\mathrm{Tg})^{\mathrm{d}}\end{array}$ \\
\hline Krakatau & Mid-August 1883 & December 1883 & 1884 & 1884 & 1884 & 44 \\
\hline Santa María & 24 Oct 1902 & February 1903 & 1903 & 1903 & 1903 & 30 \\
\hline Mount Agung & Mid-March 1963 & July 1963 & 1963 & 1964 & 1963 & 20 \\
\hline El Chichón & 28 Mar 1982 & July 1982 & 1982 & 1983 & 1982 & 7 \\
\hline Mount Pinatubo & 15 Jun 1991 & October 1991 & 1992 & 1992 & 1992 & 20 \\
\hline
\end{tabular}

${ }^{\text {a }}$ Eruption dates are from Iles et al. (2013) and Iles and Hegerl (2014). The date of Krakatau is defined when aerosol clouds can first be seen in the Crowley et al. (2008) dataset for a given eruption. Dates for other volcanoes were obtained from the Global Volcanism Project (http://www.volcano.si.edu).

${ }^{\mathrm{b}}$ The year indicated for NDJFMA represents the year for January-April.

${ }^{\mathrm{c}}$ The years are defined for analyzing R95p and SDII.

${ }^{\mathrm{d}}$ From stratospheric $\mathrm{SO}_{2}$ injection data from Stothers (1996), Bluth et al. (1997), Andres and Kasgnoc (1998), and Stothers (2001).

for each volcanic window. However, years from +1 to +3 are excluded when volcanic impacts are significantly large. To increase sample size, years $-5,+8$, and +9 are added to each window. In this way, we make 1000 random arrays and the 5th-95th-percentile ranges are estimated for a significance test of the observed response to volcanic forcing. The resulting analysis period of observations is 1957-2000 for three recent volcanoes.

\section{c. Global land and monsoon domain}

For CMIP5 models, global land area is defined where more than $25 \%$ of a grid is covered with land for each model. When displaying spatial patterns, a bilinear interpolation is applied to the model datasets onto $3.75^{\circ} \times$ $2.5^{\circ}$ grids after applying the land mask. Responses are shown where more than $70 \%$ models have records after the interpolation to avoid grids defined as land by only a few models, especially along the coastal areas. We define monsoon regions for each model, following Hsu et al. $(2011,2013)$, as regions where the annual range (difference between local summer and winter precipitation) of precipitation is greater than $2 \mathrm{~mm} \mathrm{day}^{-1}$ and the local summer precipitation exceeds $55 \%$ of the annual rainfall for the whole analysis period (1878-1998). For the monsoon area, summer (winter) is defined as May-September and winter (summer) is defined as November-March for the $\mathrm{NH}(\mathrm{SH})$.

For the observations, we define monsoon regions using a $2.5^{\circ} \times 2.5^{\circ}$ version of the Global Precipitation Climatology Project (GPCP) combined satellite-gauge dataset (Adler et al. 2003). Monsoon regions are defined in the same way as in the model after interpolating the GPCP data onto $3.75^{\circ} \times 2.5^{\circ}$ grids for the $1979-2000$ period. Results remain the same when a different period such as 1979-2010 is applied.

\section{d. Moisture budget analysis}

To explore role of thermodynamic and dynamic effects on hydrological cycle responses to volcanic eruptions, we conduct a moisture budget analysis based on the linearized formulation as used in previous studies (Seager et al. 2010; Seager and Naik 2012; Endo and Kitoh 2014):

$$
\begin{aligned}
\delta P & =\delta E+\delta \mathrm{TH}+\delta \mathrm{DY}+\delta \mathrm{NL}+\text { Res }, \\
\delta \mathrm{TH} & =-\frac{1}{\rho_{w} g} \int_{0}^{p_{s}} \nabla \cdot(\overline{\mathbf{u}}[\delta \bar{q}]) d p, \\
\delta \mathrm{DY} & =-\frac{1}{\rho_{w} g} \int_{0}^{p_{s}} \nabla \cdot([\delta \overline{\mathbf{u}}] \bar{q}) d p, \quad \text { and } \\
\delta \mathrm{NL} & =-\frac{1}{\rho_{w} g} \int_{0}^{p_{s}} \nabla \cdot(\delta \overline{\mathbf{u}} \delta \bar{q}) d p,
\end{aligned}
$$

where $P$ is precipitation, $E$ is evaporation from the surface, $\rho_{w}$ is the water density, $g$ is the acceleration of gravity, $p$ is the pressure, $p_{s}$ is the surface pressure, $\mathbf{u}$ is the horizontal wind vector, and $q$ is specific humidity. Terms representing changes in specific humidity and changes in mean circulation are called thermodynamic $\delta \mathrm{TH}$ and dynamic $\delta \mathrm{DY}$ terms, respectively. The nonlinear term with both moisture and circulation varying is indicated as $\delta N L$. The residual terms Res are a composite of transient eddies, surface quantities, and computation errors. Overbars indicate seasonal means and $\delta(\cdot)$ denotes changes resulting from volcanic eruptions as $(\cdot)_{\mathrm{VOL}}-(\cdot)_{\mathrm{REF}}$, where subscripts VOL and REF indicate the posteruption years and the preeruption 5-yr mean, respectively. Changes in transient eddy fluxes are neglected for simplicity, as they are likely to have little influence on the global monsoon area-averaged responses (see below).

\section{Results}

\section{a. Extreme temperature responses}

Spatial patterns of extreme and mean temperature responses to volcanic eruptions from ALL multimodel ensemble (MME) means are displayed in Fig. 1, which 

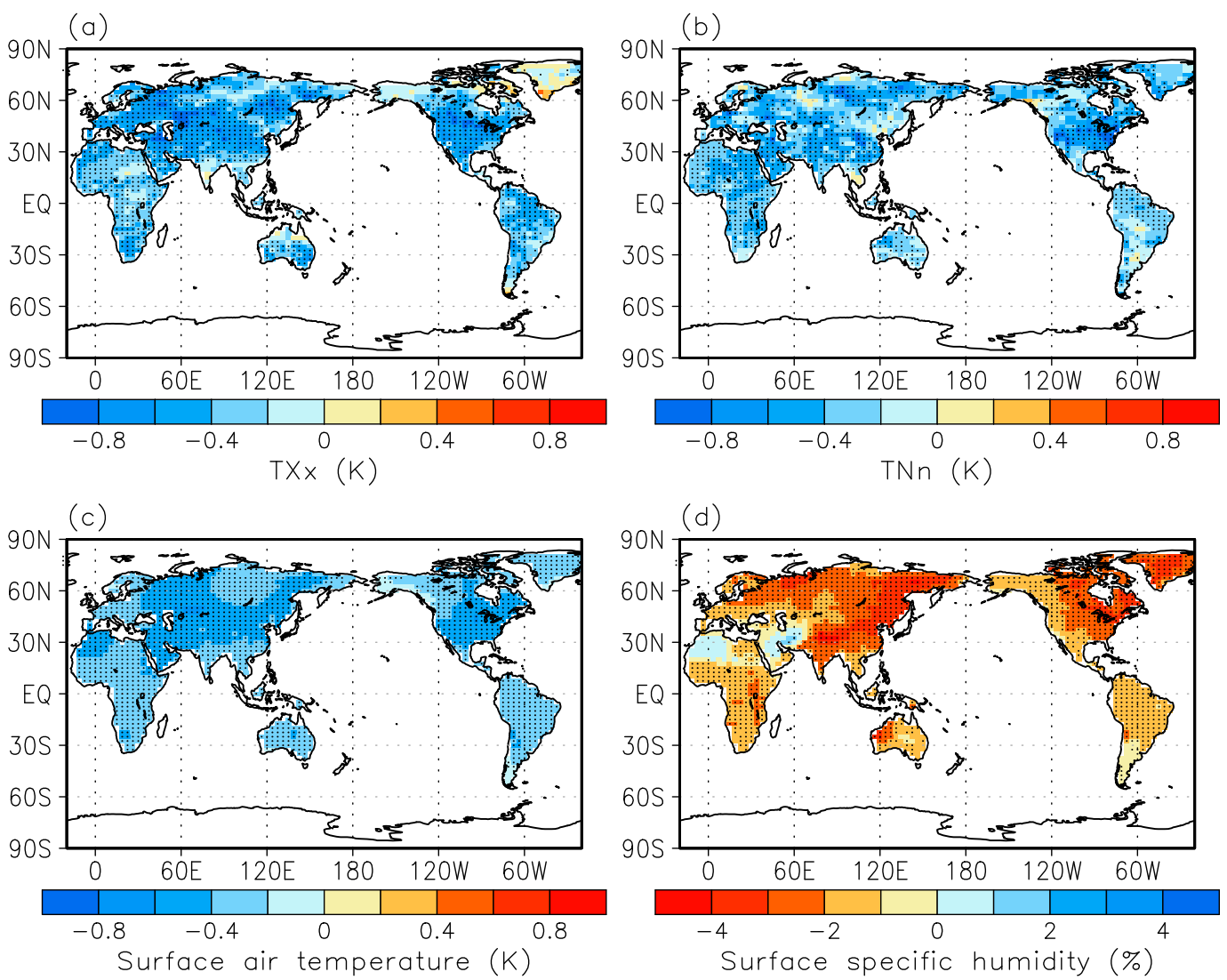

FIG. 1. Spatial patterns of multimodel-mean ALL posteruption 2-yr mean responses following five volcanic eruptions for (a) TXx, (b) TNn, (c) surface air temperature, and (d) surface specific humidity. Black dots indicate where more than $70 \%$ of models have a consistent sign for the responses.

are averages for two posteruption years. The responses show spatially homogenous temperature cooling, almost over the entirety of global lands. The responses are stronger in the midlatitudes, consistent with the previous finding (Paik and Min 2017). Furthermore, most regions have a good agreement in the sign of the model responses (more than $70 \%$ of models have an equal sign of the responses to MME values), especially in mean temperature cooling. When comparing extreme and mean responses, some regions exhibit greater cooling in extremes than means, such as Europe and northwestern North America for TXx and northern Eurasia and central Africa for TNn. Figure 1d shows surface specific humidity responses in the two posteruption years. Most global land areas experience a decrease in surface moisture after eruptions, with good intermodel agreement, as in the temperature responses.

Figure 2 shows the global land-averaged ALL and NAT composite responses of extreme and mean temperatures and specific humidity to five volcanic eruptions. Maximum cooling and drying responses occur at year +1 or year +2 in both experiments. After the maximum responses, slow recoveries are seen back to the preeruption values. NAT shows greater cooling and drying responses than ALL, because of the absence of anthropogenic warming (Willett et al. 2007; Kim et al. 2016). Gray shading indicates natural internal variability ranges, estimated as the 1st-99th-percentile ranges, from a random bootstrap approach as described above. During the four posteruption years, the cooling and drying responses of ALL exceed the internal variability ranges. Interestingly, $\mathrm{TNn}$ has maximum cooling one year later than TXx. Such later cooling of TNn is observed mainly over the northern Eurasia region, which is not seen in TXx (Fig. S1 in the supplemental material). This seems to be due to the regional winter warming occurring at year +1 associated with a positive NAO response to the volcanic forcing as Zambri and Robock (2016) found. Actually, winter months are more frequently selected as annual minima for TNn than for TXx, implying the important role of seasonality in the different responses between TNn and TXx (not shown).

To further explore the relation between the extreme and mean temperatures and the surface humidity 

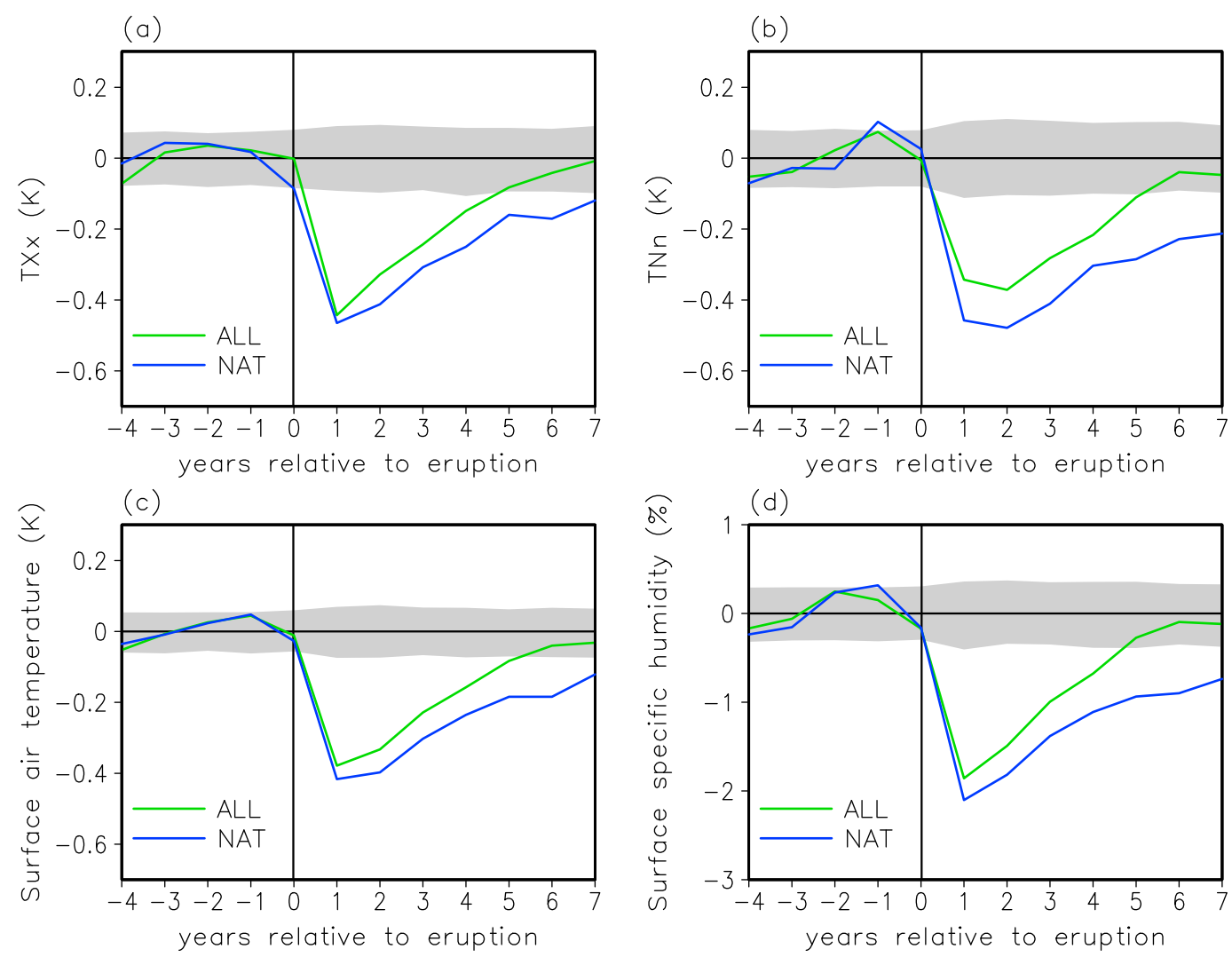

FIG. 2. Global land averaged responses of (a) TXx, (b) TNn, (c) surface air temperature, and (d) surface specific humidity to five volcanic eruptions from multimodel-mean ALL and NAT simulations. Gray shading indicates estimated natural internal variability ranges estimated from a random bootstrap approach.

responses, intermodel correlations are examined using the posteruption 2-yr mean values of 17 ALL models. Figures $3 \mathrm{a}$ and $3 \mathrm{~b}$ show that extreme temperature responses are significantly correlated with mean temperature cooling ( $r=0.91$ for TXx and 0.86 for TNn), indicating similar mechanisms operating between them. Also, Fig. 3c illustrates that surface air temperature and surface specific humidity responses are significantly correlated across models $(r=0.83)$, representing the Clausius-Clapeyron relation (Paik and Min 2017). Similar strong intermodel relationship is observed between extreme temperature and humidity (not shown). All models exhibit posteruption (2-yr mean) cooling and moisture reduction, indicating the robust responses.

\section{b. Extreme precipitation responses}

Figure 4 displays the spatial patterns of the posteruption 2-yr mean responses of annual extreme precipitation as well as mean precipitation from the ALL MME. Similar to mean precipitation change, extreme precipitation decreases are concentrated in global monsoon regions for all indices of Rx5day, R95p, and SDII, with good agreement in the sign of the model responses. The NH mid-to-high-latitude continents also exhibit precipitation decreases, but with weaker amplitudes and poor intermodel agreement (Fig. 4). However, the decrease in area-averaged precipitation over the mid-to-high latitudes are found to be significant (not shown). An intermodel correlation analysis (after excluding the northeast Asian monsoon region) suggests that the extratropical drying response is related to the thermodynamic effect caused by surface cooling and moisture reduction rather than dynamic circulation changes (not shown).

Seasonal (MJJASO and NDJFMA) responses of extreme (Rx5day) and mean precipitation are examined. The spatial patterns of the posteruption 2-yr means (Fig. 5) show that reductions in Rx5day and mean precipitation are dominated by the monsoon regions of summer hemispheres. That is, strong drying appears over the NH monsoon regions during MJJASO and over the $\mathrm{SH}$ monsoon regions during NDJFMA, which is in line with previous studies (Joseph and Zeng 2011). Table 4 summarizes the hemispheric responses of extreme and mean precipitation (annual values for SDII and $\mathrm{R} 95 \mathrm{P}$ ) averaged over summer monsoon regions 

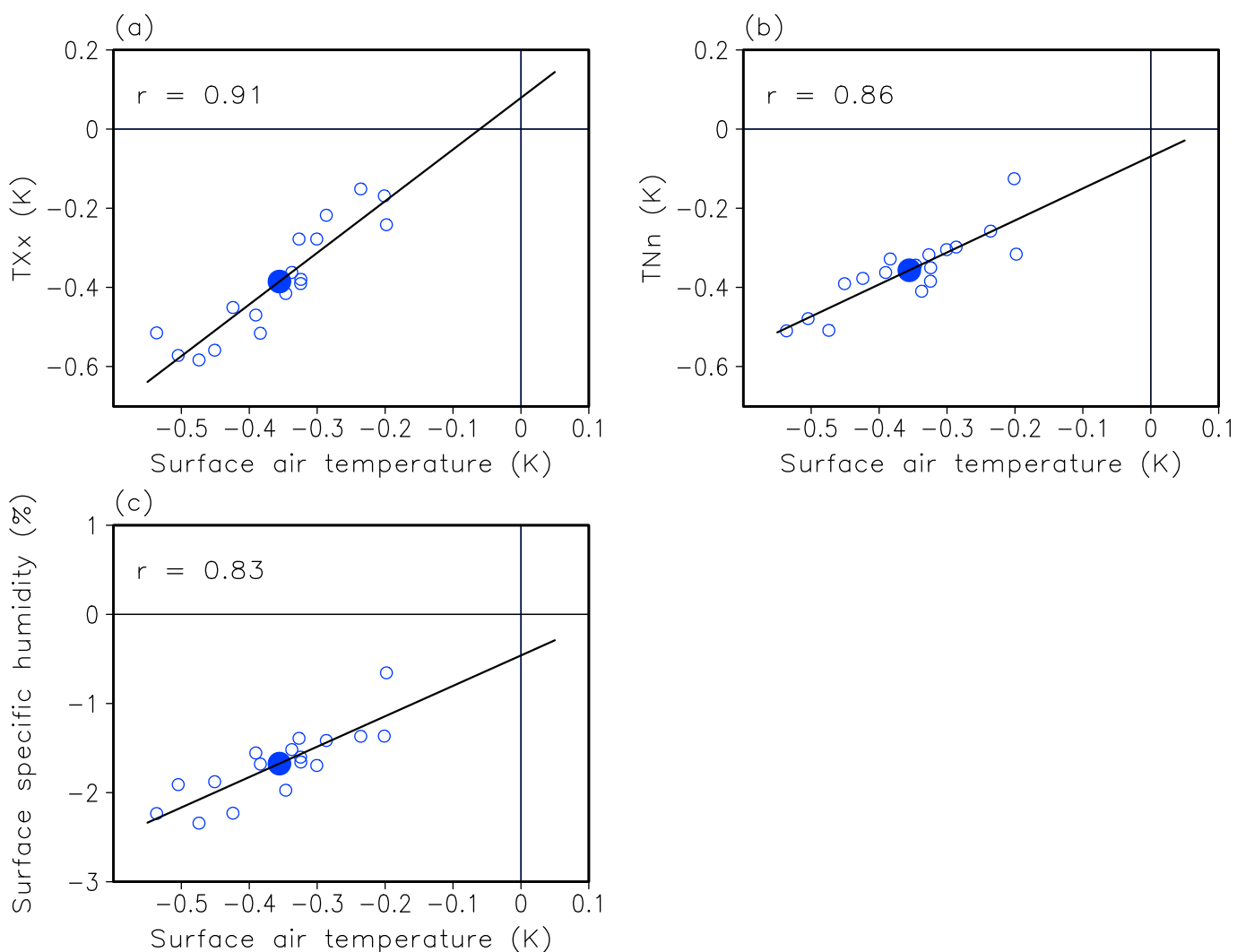

FIG. 3. Intermodel relationships between global land averaged surface air temperature and (a) TXx, (b) TNn, and (c) surface specific humidity responses. Posteruption 2-yr mean values are plotted using 17 ALL model simulations (blue open circles) and the multimodel mean (blue-filled circle). Correlation coefficients calculated using 17 model values are presented together.

during two posteruption years. The mean precipitation responses are very similar to those of extreme precipitation, showing greater amplitudes for seasonal responses in monsoon regions, consistent with Iles and Hegerl (2014). To isolate the summer monsoon responses over the globe, below we examine summed responses of the extreme and mean precipitation over the $\mathrm{NH}$ summer and SH summer monsoon regions.

Looking outside the monsoon regions, the European regions show substantial precipitation reduction in NDJFMA compared with MJJASO with a good model agreement $(>70 \%)$. We find that a positive phase of the NAO occurs at year +1 from many models, which causes anomalously wet conditions over northern Europe and dry conditions in other European regions (Fig. S2 in the supplemental material), as found in the observations (Robock and Mao 1992; Fischer et al. 2007; Wegmann et al. 2014). On the other hand, at year +2 , a negative phase of the NAO emerges also with good intermodel agreement, which induces drying over northern and central Europe and wet conditions over the Iberian Peninsula, southern Europe, the Mediterranean
Sea, and the Middle East (Fig. S2). Also, many CMIP5 models simulate dry-wet meridional dipole patterns over the North Atlantic Ocean in relation to the NAO variations (not shown). The occurrence of the negative NAO at the second year might be linked to the El Niñolike SST response, as suggested by previous studies (Brönnimann et al. 2007; Li and Lau 2012).

Figure 6 illustrates global monsoon area-averaged responses of extreme and mean precipitation from the ALL and NAT MME. For Rx5day and mean precipitation, the responses are expressed as the sum of hemispheric seasonal monsoon responses. Most of the annual responses of R95p and SDII likely come from each of the hemispheric summer monsoon values since only rain days with more than $1 \mathrm{~mm} \mathrm{day}^{-1}$ are considered to calculate the indices. Results show that global monsoon regions have large reductions in both extreme and mean precipitation, with amplitudes exceeding the internal variability ranges during the two posteruption years. Unlike the temperature and humidity responses, the ALL and NAT responses of precipitation do not have large differences, implying a weak influence of 

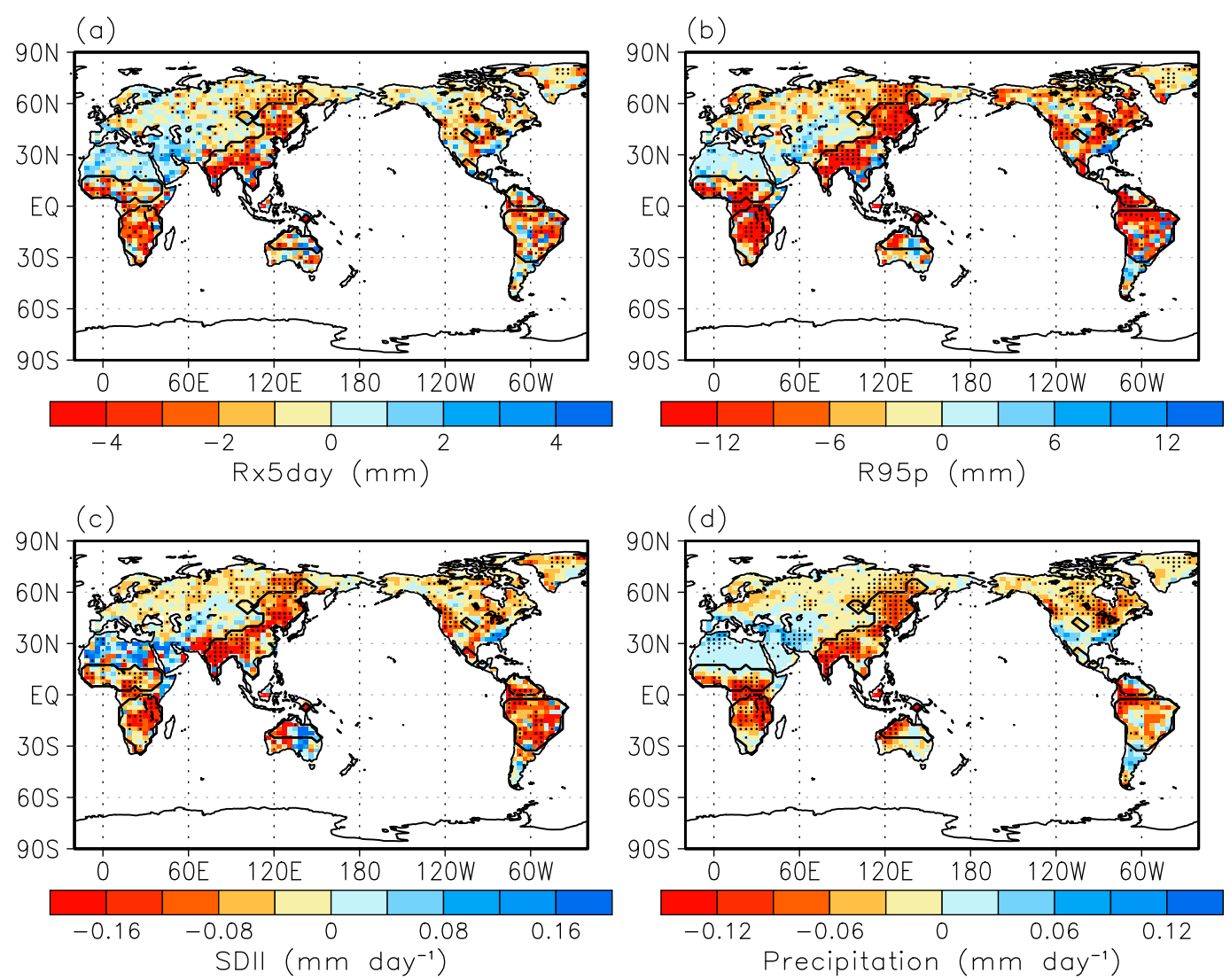

FIG. 4. Spatial patterns of multimodel-mean ALL posteruption 2-yr mean responses following five volcanic eruptions for (a) Rx5day, (b) R95p, (c) SDII, and (d) precipitation. Black dots indicate where more than $70 \%$ of models have a consistent sign for the responses. Thick black contours delineate monsoon regions defined from multimodel-mean ALL precipitation.

anthropogenic forcing on monsoon precipitation. This is consistent with the results of Paik and Min (2017), who considered recent volcanic explosions since the 1960s. Gillett et al. (2004) found a crucial influence of volcanic forcing on the terrestrial precipitation variations during 1949-98, compared to anthropogenic forcing. This weak trend in global monsoon precipitation under greenhouse warming is likely due to a large cancelation between thermodynamic contribution (moisture increase) and dynamic contribution (circulation weakening) (e.g., Held and Soden 2006; Wang et al. 2012; Endo and Kitoh 2014).

To explore whether extreme and mean precipitation decreases have a close relationship or not, intermodel relationships is analyzed using the posteruption 2-yr mean values of the 17 ALL models (Fig. 7). Interestingly, the responses of all three extreme precipitation indices show a significant correlation with the mean precipitation decrease $(r=0.63-0.76)$, suggesting that similar mechanisms are at work between the mean and extreme precipitation responses to volcanic forcing.
All models (except two models) simulate reductions in both extreme and mean precipitation, demonstrating the robustness of the global summer monsoon responses to volcanic forcing.

\section{c. Moisture budget analysis}

To explore the physical mechanisms for the hydrological cycle changes, we conduct a moisture budget analysis for the sum of $\mathrm{NH}$ and $\mathrm{SH}$ summer monsoon regions, based on the linearized formulation as described above. Figure 8a illustrates the contribution of evaporation and dynamic, thermodynamic, nonlinear, and residual terms to the precipitation decrease in years from +1 to +2 from the ALL MME. It shows that the evaporation decrease has some contribution, although the precipitation decrease from anomalous moisture divergence could lead to evaporation decrease (Joseph and Zeng 2011; Paik and Min 2017). Dynamic monsoon circulation weakening has the largest contribution, but for year +1 . The thermodynamic contribution also has strong influences in years +1 and +2 , with similar 

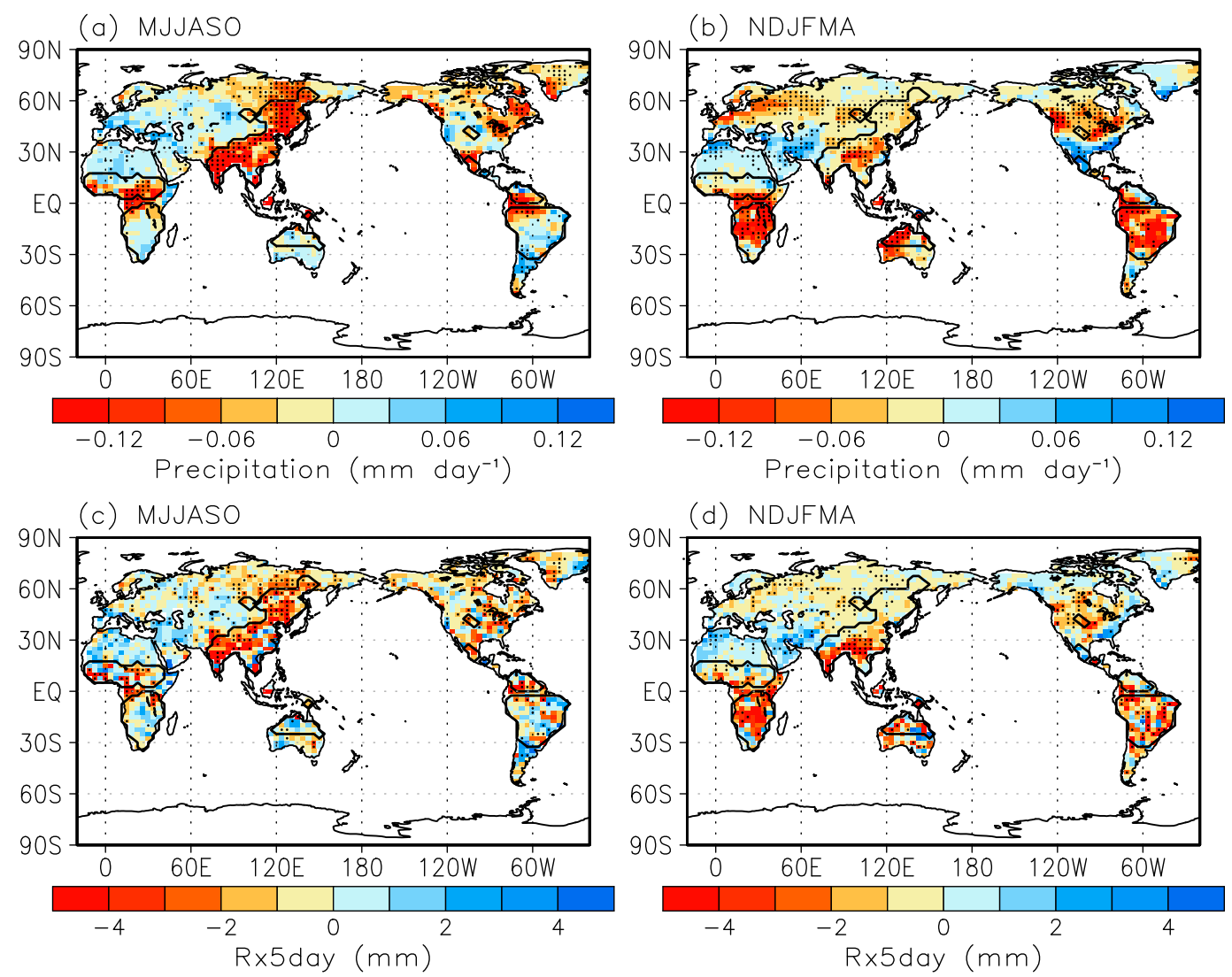

FIG. 5. Spatial patterns of multimodel-mean ALL posteruption seasonal 2-yr mean responses following five volcanic eruptions for (top) precipitation and (bottom) Rx5day, for (a),(c) MJJASO (boreal summer) and (b),(d) NDJFMA (boreal winter). Black dots indicate where more than $70 \%$ of models have a consistent sign for the responses. Thick black contours delineate monsoon regions defined from multimodel-mean ALL precipitation.

amplitudes. All the contribution of evaporation and dynamic and thermodynamic terms are significant beyond the estimated internal variability ranges (Fig. S3 in the supplemental material). Furthermore, CMIP5 models exhibit a large intermodel spread for precipitation responses in the posteruption years (Fig. 8a). Interestingly, the dynamic term makes the largest contribution to the intermodel uncertainties in precipitation response, while evaporation and thermodynamic term have much smaller spread. Nonlinear and residual terms have relatively small influences. NAT results for the moisture budget responses largely resemble those of ALL (not shown). In short, dynamic and thermodynamic contributions and evaporation changes are found to be crucial to the precipitation decrease over the summer monsoon regions.

Spatial patterns of evaporation and dynamic and thermodynamic terms are analyzed for MJJASO and NDJFMA (Figs. 8b-g). Posteruption 2-yr mean responses are displayed for evaporation and thermodynamic term while year +1 response is shown for the dynamic contribution when significant changes are observed. It can be seen that the contributions of the three terms are predominant over each hemispheric summer monsoon regions, as in the precipitation reductions (Fig. 5). However, some heterogeneous patterns appear in the dynamic contribution, particularly over South America and North Africa. These sporadic patterns in the dynamic term might be due to the low vertical

TABLE 4. Extreme and mean precipitation responses averaged over each hemisphere's summer (annual values for R95p and SDII) monsoon region calculated from the ALL MME during two posteruption years.

\begin{tabular}{|c|c|c|c|c|}
\hline \multirow[b]{2}{*}{ Variable } & \multicolumn{2}{|c|}{$\begin{array}{c}\text { Northern } \\
\text { Hemisphere }\end{array}$} & \multicolumn{2}{|c|}{$\begin{array}{c}\text { Southern } \\
\text { Hemisphere }\end{array}$} \\
\hline & $+1 \mathrm{yr}$ & $+2 \mathrm{yr}$ & $+1 \mathrm{yr}$ & $+2 \mathrm{yr}$ \\
\hline Rx5day (mm) & -2.81 & -1.05 & -2.39 & -1.33 \\
\hline $\mathrm{R} 95 \mathrm{p}(\mathrm{mm})$ & -16.90 & -6.65 & -14.85 & -8.56 \\
\hline SDII $\left(\mathrm{mm} \mathrm{day}^{-1}\right)$ & -0.13 & -0.07 & -0.12 & -0.07 \\
\hline Precipitation $\left(\mathrm{mm}\right.$ day $\left.^{-1}\right)$ & -0.15 & -0.04 & -0.17 & -0.09 \\
\hline
\end{tabular}



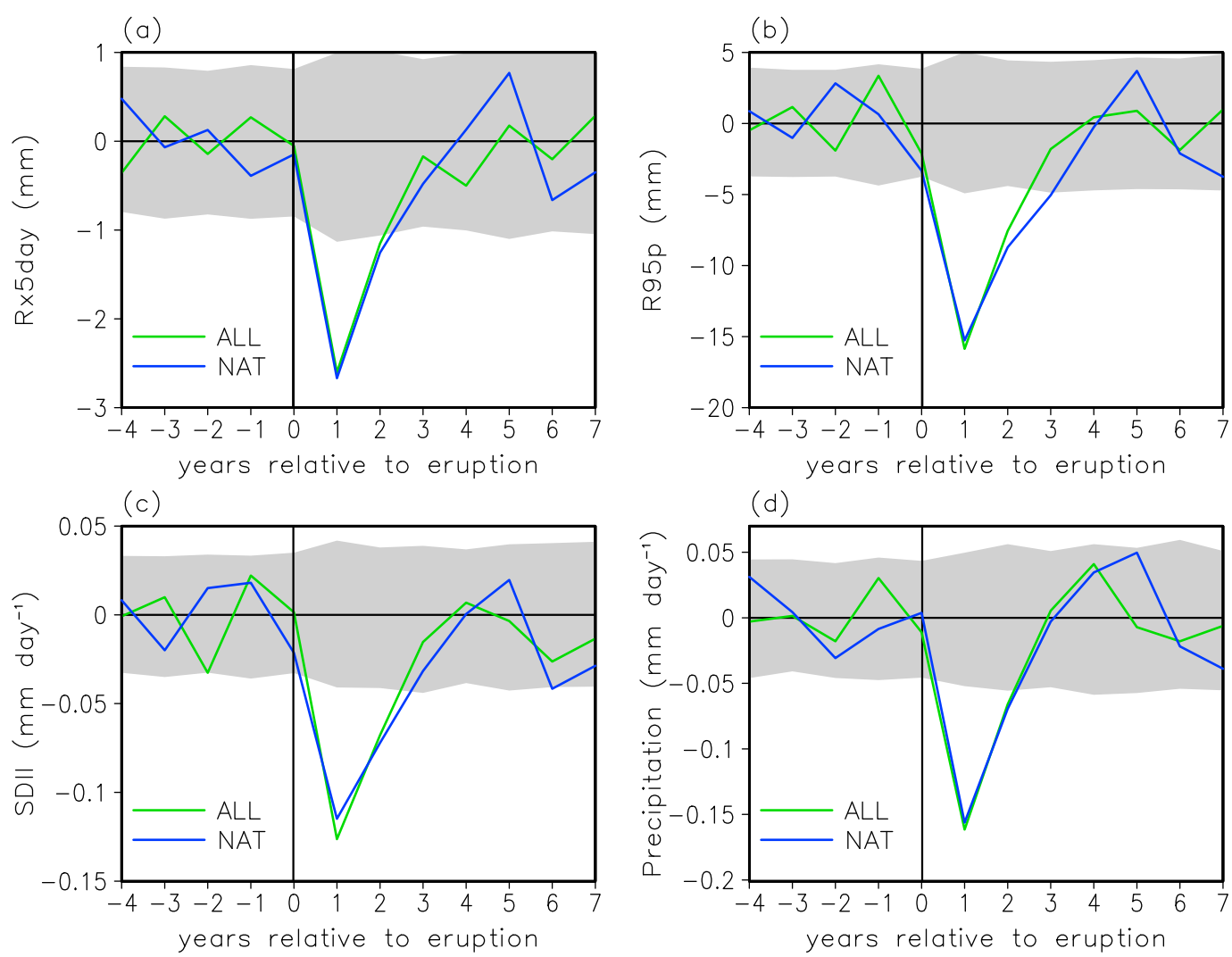

FIG. 6. (a) Rx5day, (b) R95p, (c) SDII, and (d) precipitation responses to five volcanic eruptions over the global monsoon areas (sum of $\mathrm{NH}$ and $\mathrm{SH}$ summer monsoon regions for Rx5day and precipitation) from multimodelmean ALL and NAT simulations. Gray shading indicates estimated natural internal variability ranges.

resolution and complicated topography, as previous studies pointed out (Seager et al. 2010; Endo and Kitoh 2014). When using 500-hPa vertical pressure velocity, clear divergence anomalies are present over these regions (not shown). Nevertheless, our moisture budget analysis provides a reasonable way to analyze regional monsoon responses with relatively small residuals remaining (Fig. 8a). Comparison with the spatial pattern of seasonal precipitation responses (Fig. 5) suggests that regional precipitation response can be dominated by different factors. For example, evaporation is more important for the northeast Asian precipitation change whereas winter precipitation decreases over South Asia are due mostly to evaporation and dynamical terms.

To further explore the role of dynamic contributions to the uncertainty in hydrological responses to volcanic forcing, we examine the intermodel relationship using posteruption 2-yr mean values from the 17 ALL models (Fig. 9). The results show that all extreme precipitation indices (Rx5day, R95p, and SDII) and mean precipitation decreases have significant correlations with the dynamic contribution $(r=$ $0.50-0.90)$. This clearly indicates that large intermodel uncertainty in extreme and mean precipitation responses to volcanic forcing mainly arises from the uncertainty in dynamic contributions across the CMIP5 models. This is consistent with Freychet et al. (2015), who suggested the important role of dynamic effect in the uncertain future projections of extreme precipitation over the Asian summer monsoon regions. The Rx5day responses also have significant intermodel correlations with the thermodynamic contribution ( $r=0.51$; not shown), representing significant role of the moisture availability in determining more-extreme precipitation, as suggested by previous studies (e.g., Allen and Ingram 2002; Min et al. 2011).

In the hydrological response analysis, we examine the summer monsoon regions defined from each CMIP5 model following the definition of Hsu et al. (2011, 2013). However, Hsu et al. (2013) suggested that some models overestimate or underestimate the areas although most of the CMIP5 models reproduce the major monsoon regions reasonably well. They further noted that global monsoon areas derived from MME precipitation show better agreement with the observed. In this respect, we 

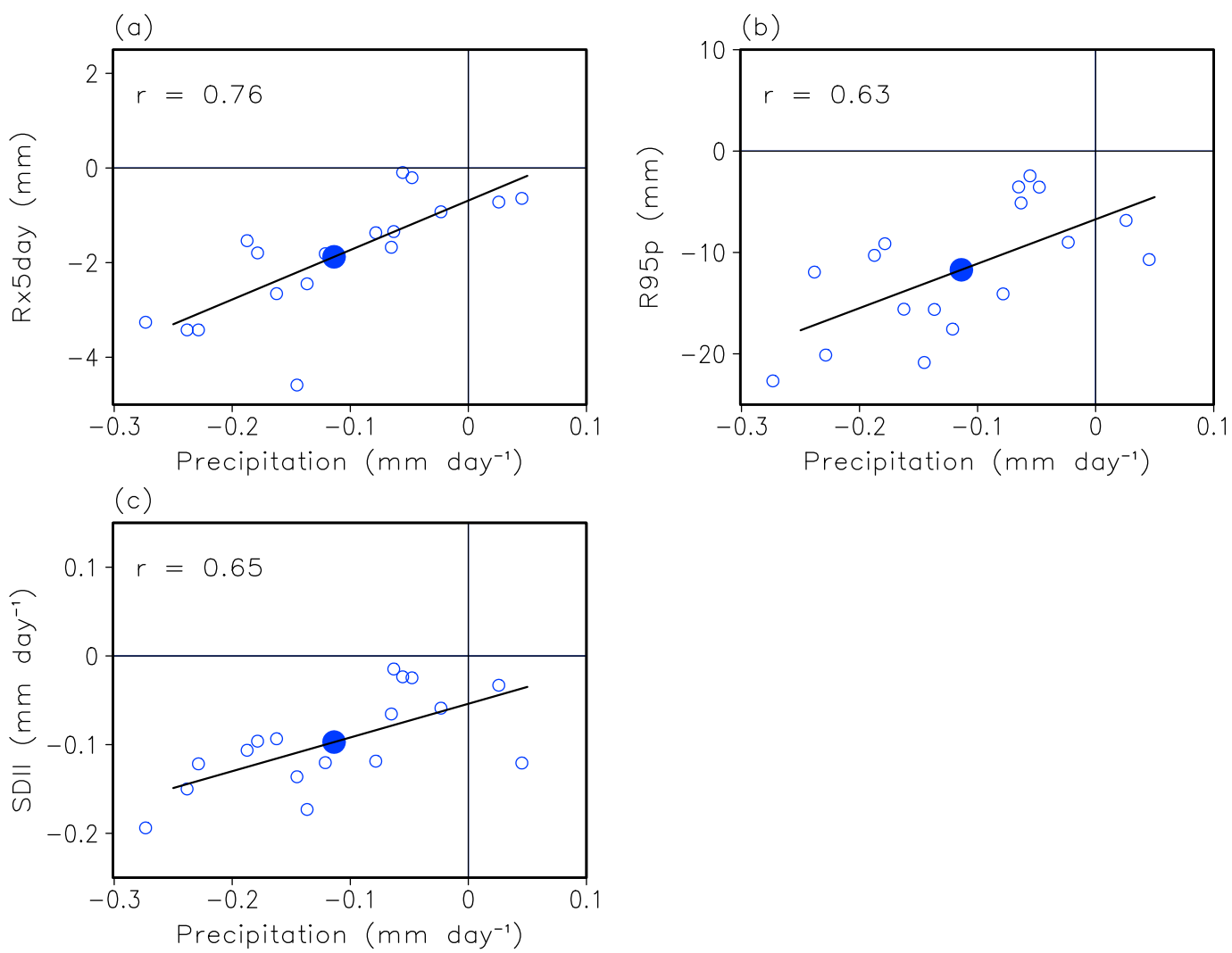

FIG. 7. Intermodel relationships between global monsoon region averaged precipitation and (a) Rx5day, (b) R95p, and (c) SDII (sum of NH and SH summer monsoon regions for Rx5day and precipitation). Posteruption 2-yr mean values are plotted using 17 ALL model simulations (blue open circles) and multimodel mean (blue-filled circle). Correlation coefficients calculated using 17 model values are presented together.

repeated our analysis using the monsoon domain defined from the MME precipitation, and obtained similar results.

\section{d. Observational analysis}

To evaluate the model-simulated extreme climate responses to five volcanic eruptions, we analyze the HadEX2 observations considering three recent volcanic eruptions. Results show that TXx has a significant decrease at year +2 beyond the estimated internal variability ranges (Fig. 10a). Compared to CMIP5 model results, the observed TXx exhibits 1-yr delayed maximum cooling. This discrepancy seems to be due to the larger positive NAO-induced warming in the observations than in the CMIP5 results. CMIP5 models also simulate the positive NAO responses after the eruption but with weaker amplitudes. This underestimation brings weaker warming over northern Eurasia (Zambri and Robock 2016), presumably inducing greater cooling at year +1 in the CMIP5 models. Another possible factor is a stronger El Niño occurrence at year +1 in the observations, which can cause anomalous warming
(Paik and Min 2017). On the other hand, TNn does not show a significant response at years from +1 to +2 , but rather has a large cooling at year +3 (Fig. 10b). This weak cooling signal in $\mathrm{TNn}$ might be linked to the stronger influence of the positive NAO during the boreal winter when $\mathrm{TNn}$ has a strong variability. Indeed, the individual model responses exhibit a larger intermodel difference for TNn than for TXx (Fig. S4 in the supplemental material), suggesting that the TNn - TXx difference can be due to natural internal variability. Overall results were very similar when using extreme temperature indices calculated from other observations [Hadley Centre Global Historical Climatology Network-Daily data (HadGHCND; Caesar et al. 2006; not shown].

Figure 10c shows the Rx5day response (sum of $\mathrm{NH}$ and SH summer monsoon regions) from the HadEX2 observations. There is substantial reduction at year +1 , below the 5th percentile of random samples. Although R95p does not have any significant change, SDII is significantly reduced at year +1 (Figs. 10d,e). Overall, the HadEX2 observations show limited evidence of significant extreme 

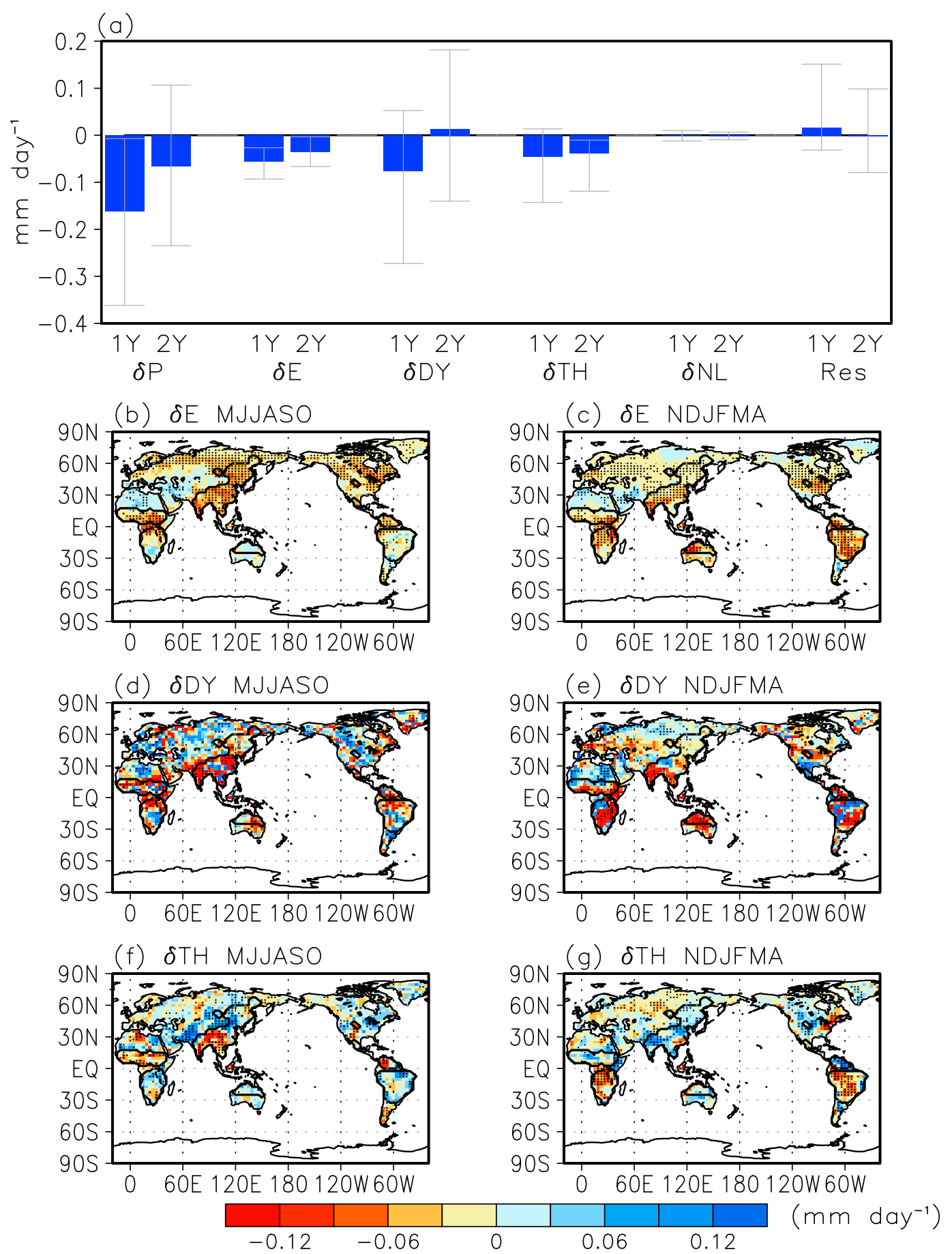

FIG. 8. (a) Moisture budgets for five volcanic eruptions over monsoon regions (sum of NH and SH summer monsoon regions): changes in precipitation $\delta P$ and evaporation $\delta E$ and $\delta \mathrm{DY}, \delta \mathrm{TH}, \delta \mathrm{NL}$, and Res terms obtained from ALL multimodel mean. For each component, years from +1 to +2 are plotted from left to right. Gray error bars indicate 17 ALL model ranges. Also shown are spatial patterns of multimodel-mean ALL responses for (b),(c) $\delta E,(\mathrm{~d}),(\mathrm{e}) \delta \mathrm{DY}$, and (f), (g) $\delta \mathrm{TH}$ contributions posteruption 2 -yr mean (1 yr for dynamic contribution) following five volcanic eruptions in boreal (b),(d),(f) summer and (c),(e),(g) winter. Black dots indicate where more than $70 \%$ of models have a consistent sign for the responses. 

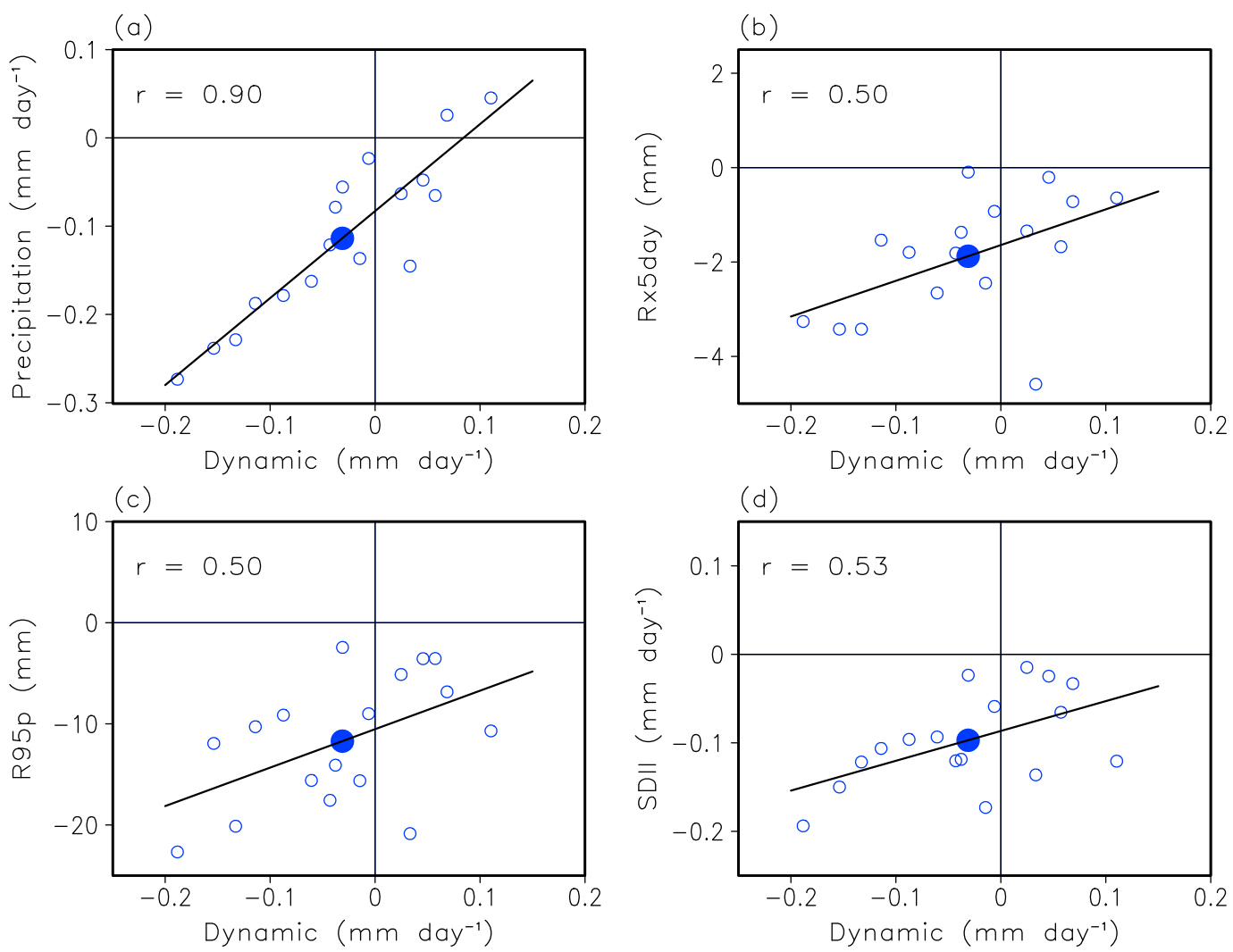

FIG. 9. (a) Intermodel relationships between dynamic contribution and (a) Rx5day, (b) R95p, (c) SDII, and (d) precipitation over global monsoon region (sum of NH and SH summer monsoon regions for dynamic contribution, Rx5day, and precipitation). Posteruption 2-yr mean values are plotted using 17 ALL model simulations (blue open circles) and multimodel mean (blue-filled circle). Correlation coefficients calculated using 17 model values are presented together.

climate responses during the posteruption years. This weaker signal is expected because the three latest volcanic eruptions were considered due to the limited data coverage. The observational extreme climate response is spatially heterogeneous especially for precipitation, indicating stronger influences of natural internal variabilities (Figs. S5 and S6). This discrepancy between CMIP5 models and observations can also be due to some uncertain physical processes (e.g., clouds and atmospheric convection) and biases in the models (e.g., monsoon climatology) (Flato et al. 2013). Nevertheless, these observation-based results well support the model-based finding: the cooling of extreme temperatures and the weakening of extreme precipitation after explosive tropical volcanic eruptions.

\section{Summary and discussion}

Understanding variability and changes in climate extremes is fundamental because of their stronger impacts on human society and the ecosystem. This study provides a first analysis of extreme climate responses to volcanic forcing using CMIP5 multimodel simulations. Multimodel-mean responses to five explosive tropical volcanic eruptions since the 1880s are examined for temperature and precipitation extremes and results are compared with mean climate responses. During posteruption years, models consistently simulate decreases in extreme temperature ( $\mathrm{TXx}$ and $\mathrm{TNn}$ ) in line with the decreases in mean temperature and surface moisture over the global land. The responses peak at year +1 or +2 following the volcanic eruptions, which are statistically significant beyond the ranges of natural internal variability. To understand the relationship between the extreme and mean climate responses, the intermodel relationship between variables is examined. A very strong intermodel correlation is obtained between extreme and mean temperature cooling, indicating that similar mechanisms are operating. Also, mean and extreme temperature decrease is found to be related to surface drying, consistent with the Clausius-Clapeyron relation. It is demonstrated that all CMIP5 models have cooling and drying responses following volcanic eruptions, representing the robustness of the responses. 

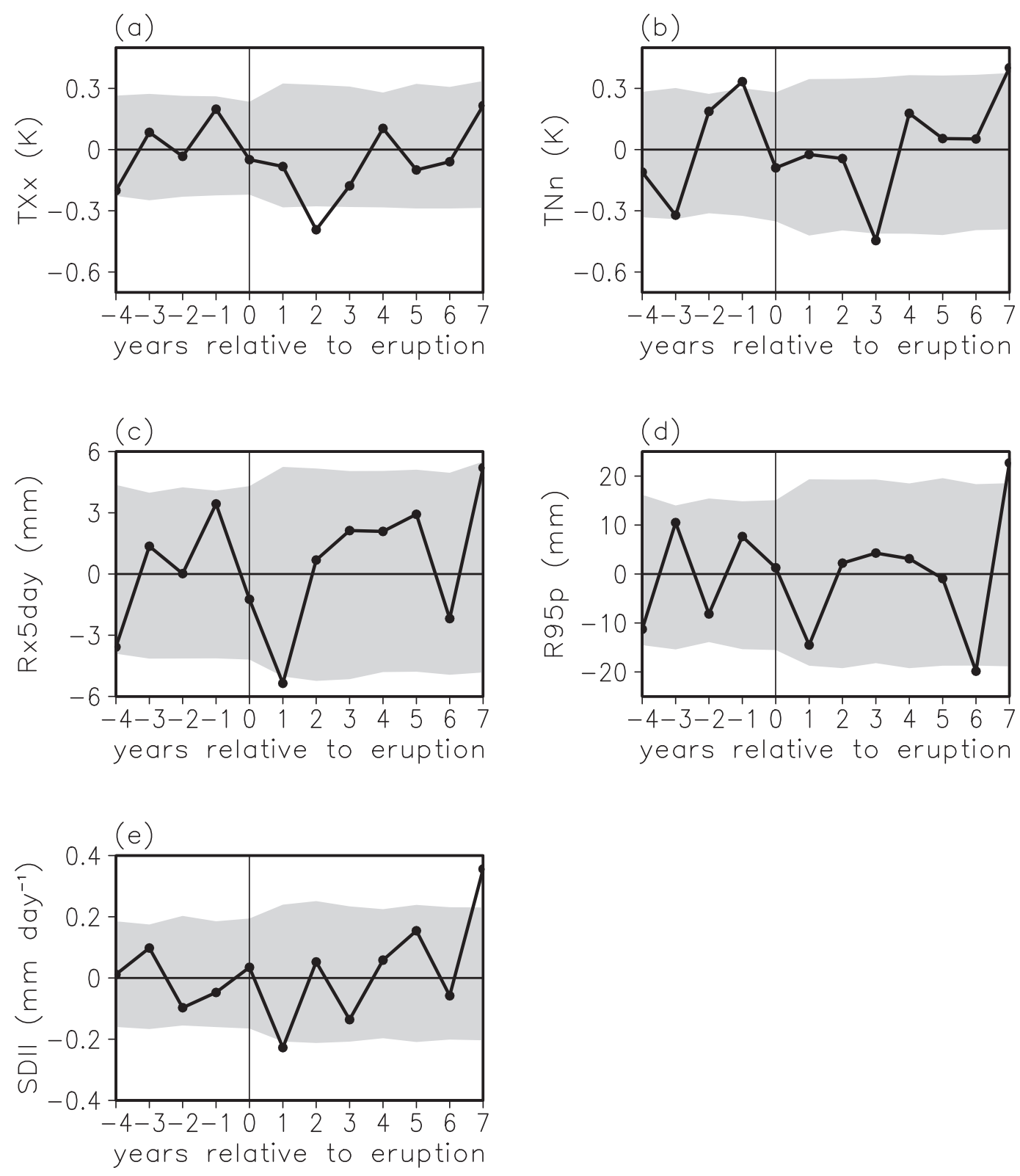

FIG. 10. (a) TXx, (b) TNn, (c) Rx5day, (d) R95p, and (e) SDII responses to three volcanic eruptions over the global land (TXx and TNn), sum of NH and SH summer monsoon regions (Rx5day), and global monsoon regions (R95p and SDII) from HadEX2 observations. Gray shading indicates 5th-95th-percentile ranges from 1000 random bootstrapping samples (natural internal variability ranges) estimated from the observations. See text for details.

Extreme precipitation responses to volcanic forcing are analyzed using three indices (Rx5day, R95p, and SDII). Distinct reductions in extreme and mean precipitation appear over the Northern and Southern Hemisphere summer monsoon regions after volcanic eruptions. The precipitation decreases are also greater than the derived internal variability ranges. The extreme precipitation changes are found to be closely related to the mean precipitation response over the monsoon regions across models. To better understand the mechanisms associated with the precipitation reduction, the moisture budget is examined. Results show that evaporation and divergence from thermodynamic and dynamic effects mainly contribute to the precipitation decrease over the global monsoon regions. In particular, the dynamic term has a large influence at year +1 , whereas the thermodynamic term affects years +1 and +2 . In addition, the dynamic contribution is found to exert the largest 
influence on intermodel spread in the CMIP5 models' precipitation responses, with high intermodel correlations with mean and extreme precipitation changes. This confirms the important role of the dynamic effect (atmospheric circulation responses) in the intermodel differences in hydrological changes under volcanic forcing, implying that further understanding of the causes of the diverse responses in dynamic terms are needed.

Observational analysis using the three recent volcanoes is conducted to evaluate model simulated results. Results suggest a significant decrease in the observed TXx at year +2 , but no strong response is identified in TNn except at year +3 . The latter seems to be partly due to a positive NAO response in the observations, which warms northern Eurasia during the two posteruption years, weakening volcanic cooling responses. In addition, a simple examination of the individual model responses suggests a larger spread of peak cooling years for TNn than for TXx, which indicates more diverse influences of natural internal variability during boreal winter season when $\mathrm{TNn}$ has a strong variability. Also, a substantial reduction in Rx5day and SDII is found at year +1 over the global summer monsoon regions but R95p does not show significant changes. Considering the limited data coverage and shorter time period, this observed evidence well supports the model-based results.

It should be noted that El Niño influences could be contained in the posteruption year responses but have not been considered in this study. Many studies suggested increased occurrences of El Niño-Southern Oscillation (ENSO) following volcanic eruptions (Adams et al. 2003; Maher et al. 2015; Lim et al. 2016). In particular, Maher et al. (2015) suggested an increase in ENSO after the eruptions using CMIP5 models. Analyzing observations, Khodri et al. (2017) showed that the probability of having El Niño events following four out of five volcanic eruptions is very low. Also, the modeling study of Stevenson et al. (2016) suggested that El Niño occurrence with the volcanic eruptions can amplify the precipitation responses to volcanic forcing over Southeast Asia and the western United States. Therefore, future studies are warranted to understand details of how volcanic impacts on climate extremes are modified through ENSO teleconnection.

The results from this study have some important implications for geoengineering based on solar radiation management. Geoengineering has received attention as a possible solution to anthropogenic warming (Govindasamy and Caldeira 2000). Previous geoengineering experiment studies suggested that even if the global mean surface temperature is approximately restored to preindustrial levels, the geographical patterns of mean and extreme temperatures can be significantly different (Kravitz et al. 2013; Curry et al. 2014), mechanisms of which are closely related to that of volcanic cooling. More importantly, mean and extreme precipitation are expected to decrease instantaneously responding to the reduced solar radiation (Tilmes et al. 2013; Curry et al. 2014). Such changes in precipitation patterns would have huge impacts on human society and the ecosystem through droughts and agriculture failure. However, models are known to underestimate the observed precipitation response to volcanic forcing (Gillett et al. 2004; Hegerl and Solomon 2009), as we showed above. In this context, exploring causes of the model-observation discrepancy remains an important issue.

Acknowledgments. This work was supported by a National Research Foundation of Korea (NRF) grant funded by the South Korean government (MSIT) (Grant 2017R1A2B2008951) and by the Korea Meteorological Administration Research and Development Program under Grant KMI 2018-03610. We acknowledge the World Climate Research Programme's Working Group on Coupled Modelling, which is responsible for CMIP, and we thank the climate modeling groups (listed in Table 1 of this paper) for producing and making available their model output.

\section{REFERENCES}

Adams, J. B., M. E. Mann, and C. M. Ammann, 2003: Proxy evidence for an El Niño-like response to volcanic forcing. Nature, 426, 274-278, https://doi.org/10.1038/nature02101.

Adler, R. F., and Coauthors, 2003: The version-2 Global Precipitation Climatology Project (GPCP) monthly precipitation analysis (1979-present). J. Hydrometeor., 4, 1147-1167, https://doi.org/ 10.1175/1525-7541(2003)004<1147:TVGPCP > 2.0.CO;2.

Allen, M. R., and W. J. Ingram, 2002: Constraints on future changes in climate and the hydrological cycle. Nature, 419, 224-232, https://doi.org/10.1038/nature01092.

Andres, R. J., and A. D. Kasgnoc, 1998: A time-averaged inventory of subaerial volcanic sulfur emissions. J. Geophys. Res., 103, 25 251-25 261, https://doi.org/10.1029/98JD02091.

Barnes, E. A., S. Solomon, and L. M. Polvani, 2016: Robust wind and precipitation responses to the Mount Pinatubo eruption, as simulated in the CMIP5 models. J. Climate, 29, 4763-4778, https://doi.org/10.1175/JCLI-D-15-0658.1.

Barnes, J. E., and D. J. Hofmann, 1997: Lidar measurements of stratospheric aerosol over Mauna Loa Observatory. Geophys. Res. Lett., 24, 1923-1926, https://doi.org/10.1029/97GL01943.

Bittner, M., H. Schmidt, C. Timmreck, and F. Sienz, 2016: Using a large ensemble of simulations to assess the Northern Hemisphere stratospheric dynamical response to tropical volcanic eruptions and its uncertainty. Geophys. Res. Lett., 43, 93249332, https://doi.org/10.1002/2016GL070587.

Bluth, G. J. S., W. I. Rose, I. E. Sprod, and A. J. Krueger, 1997: Stratospheric loading of sulfur from explosive volcanic eruptions. J. Geol., 105, 671-683, https://doi.org/10.1086/515972.

Brönnimann, S., E. Xoplaki, C. Casty, A. Pauling, and J. Luterbacher, 2007: ENSO influence on Europe during the last centuries. Climate Dyn., 28, 181-197, https://doi.org/ 10.1007/s00382-006-0175-z. 
Caesar, J., L. Alexander, and R. Vose, 2006: Large-scale changes in observed daily maximum and minimum temperatures: Creation and analysis of a new gridded data set. J. Geophys. Res., 111, D05101, https://doi.org/10.1029/ 2005JD006280.

Crowley, T. J., G. Zielinski, B. Vinther, R. Udisti, K. Kreutz, J. Cole-Dai, and E. Castellano, 2008: Volcanism and the Little Ice Age. PAGES News, Vol. 16, PAGES International Project Office, Bern, Switzerland, 22-23.

Curry, C. L., and Coauthors, 2014: A multimodel examination of climate extremes in an idealized geoengineering experiment. J. Geophys. Res. Atmos., 119, 3900-3923, https://doi.org/10.1002/2013JD020648.

Donat, M. G., and Coauthors, 2013: Updated analyses of temperature and precipitation extreme indices since the beginning of the twentieth century: The HadEX2 dataset. J. Geophys. Res. Atmos., 118, 2098-2118, https://doi.org/10.1002/jgrd.50150.

Driscoll, S., A. Bozzo, L. J. Gray, A. Robock, and G. Stenchikov, 2012: Coupled Model Intercomparison Project 5 (CMIP5) simulations of climate following volcanic eruptions. J. Geophys. Res., 117, D17105, https://doi.org/10.1029/ 2012JD017607.

Endo, H., and A. Kitoh, 2014: Thermodynamic and dynamic effects on regional monsoon rainfall changes in a warmer climate. Geophys. Res. Lett., 41, 1704-1710, https://doi.org/10.1002/ 2013 GL059158.

Fischer, E. M., J. Luterbacher, E. Zorita, S. F. B. Tett, C. Casty, and H. Wanner, 2007: European climate response to tropical volcanic eruptions over the last half millennium. Geophys. Res. Lett., 34, L05707, https://doi.org/10.1029/2006GL027992.

Flato, G., and Coauthors, 2013: Evaluation of climate models. Climate Change 2013: The Physical Science Basis, T. Stocker et al., Eds., Cambridge University Press, 741-866.

Freychet, N., H.-H. Hsu, C. Chou, and C.-H. Wu, 2015: Asian summer monsoon in CMIP5 projections: A link between the change in extreme precipitation and monsoon dynamics. J. Climate, 28, 1477-1493, https://doi.org/10.1175/ JCLI-D-14-00449.1.

Gillett, N. P., A. J. Weaver, F. W. Zwiers, and M. F. Wehner, 2004: Detection of volcanic influence on global precipitation. Geophys. Res. Lett., 31, L12217, https://doi.org/10.1029/ 2004 GL020044.

Govindasamy, B., and K. Caldeira, 2000: Geoengineering Earth's radiation balance to mitigate $\mathrm{CO}_{2}$-induced climate change. Geophys. Res. Lett., 27, 2141-2144, https://doi.org/10.1029/ 1999GL006086.

Hegerl, G. C., and S. Solomon, 2009: Risks of climate engineering. Science, 325, 955-956, https://doi.org/10.1126/ science. 1178530 .

Held, I. M., and B. J. Soden, 2006: Robust responses of the hydrological cycle to global warming. J. Climate, 19, 5686-5699, https://doi.org/10.1175/JCLI3990.1.

Hsu, P.-C., T. Li, and B. Wang, 2011: Trends in global monsoon area and precipitation over the past 30 years. Geophys. Res. Lett., 38, L08701, https://doi.org/10.1029/2011GL046893.

—_ - _ H. Murakami, and A. Kitoh, 2013: Future change of the global monsoon revealed from 19 CMIP5 models. J. Geophys. Res. Atmos., 118, 1247-1260, https://doi.org/ 10.1002/jgrd.50145.

Iles, C. E., and G. C. Hegerl, 2014: The global precipitation response to volcanic eruptions in the CMIP5 models. Environ. Res. Lett., 9, 104012, https://doi.org/10.1088/1748-9326/9/10/ 104012.
— - - A. P. Schurer, and X. Zhang, 2013: The effect of volcanic eruptions on global precipitation. J. Geophys. Res. Atmos., 118, 8770-8786, https://doi.org/10.1002/jgrd.50678.

IPCC, 2012: Managing the Risks of Extreme Events and Disasters to Advance Climate Change Adaptation. Cambridge University Press, $582 \mathrm{pp}$.

Joseph, R., and N. Zeng, 2011: Seasonally modulated tropical drought induced by volcanic aerosol. J. Climate, 24, 20452060, https://doi.org/10.1175/2009JCLI3170.1.

Khodri, M., and Coauthors, 2017: Tropical explosive volcanic eruptions can trigger El Niño by cooling tropical Africa. Nat. Commun., 8, 778, https://doi.org/10.1038/s41467-017-00755-6.

Kim, Y.-H., S.-K. Min, X. Zhang, F. Zwiers, L. V. Alexander, M. G. Donat, and Y.-S. Tung, 2016: Attribution of extreme temperature changes during 1951-2010. Climate Dyn., 46, 1769-1782, https://doi.org/10.1007/s00382-015-2674-2.

Kravitz, B., and Coauthors, 2013: Climate model responses from the Geoengineering Model Intercomparison Project (GeoMIP). J. Geophys. Res. Atmos., 118, 8320-8332, https:// doi.org/10.1002/jgrd.50646.

Li, Y., and N.-C. Lau, 2012: Impact of ENSO on the atmospheric variability over the North Atlantic in late winter-Role of transient eddies. J. Climate, 25, 320-342, https://doi.org/ 10.1175/JCLI-D-11-00037.1.

Lim, H.-G., S.-W. Yeh, J.-S. Kug, Y.-G. Park, J.-H. Park, R. Park, and C.-K. Song, 2016: Threshold of the volcanic forcing that leads the El Niño-like warming in the last millennium: Results from the ERIK simulation. Climate Dyn., 46, 3725-3736, https://doi.org/10.1007/s00382-015-2799-3.

Liu, F., J. Chai, B. Wang, J. Liu, X. Zhang, and Z. Wang, 2016: Global monsoon precipitation responses to large volcanic eruptions. Sci. Rep., 6, 24331, https://doi.org/10.1038/ srep24331.

Maher, N., S. McGregor, M. H. England, and A. Sen Gupta, 2015: Effects of volcanism on tropical variability. Geophys. Res. Lett., 42, 6024-6033, https://doi.org/10.1002/2015GL064751.

Min, S.-K., X. Zhang, F. W. Zwiers, and G. C. Hegerl, 2011: Human contribution to more-intense precipitation extremes. Nature, 470, 378-381, https://doi.org/10.1038/nature09763.

Paik, S., and S.-K. Min, 2017: Climate responses to volcanic eruptions assessed from observations and CMIP5 multimodels. Climate Dyn., 48, 1017-1030, https://doi.org/ 10.1007/s00382-016-3125-4.

Robock, A., and J. Mao, 1992: Winter warming from large volcanic eruptions. Geophys. Res. Lett., 19, 2405-2408, https://doi.org/ 10.1029/92GL02627.

— and - 1995: The volcanic signal in surface temperature observations. J. Climate, 8, 1086-1103, https://doi.org/10.1175/ 1520-0442(1995)008<1086:TVSIST > 2.0.CO;2.

Seager, R., and N. Naik, 2012: A mechanisms-based approach to detecting recent anthropogenic hydroclimate change. J. Climate, 25, 236-261, https://doi.org/10.1175/ JCLI-D-11-00056.1.

,-- , and G. A. Vecchi, 2010: Thermodynamic and dynamic mechanisms for large-scale changes in the hydrological cycle in response to global warming. J. Climate, 23, 4651-4668, https://doi.org/10.1175/2010JCLI3655.1.

Stevenson, S., B. Otto-Bliesner, J. Fasullo, and E. Brady, 2016: “El Niño like" hydroclimate responses to last millennium volcanic eruptions. J. Climate, 29, 2907-2921, https://doi.org/10.1175/ JCLI-D-15-0239.1.

Stothers, R. B., 1996: Major optical depth perturbations to the stratosphere from volcanic eruptions: Pyrheliometric period, 
1881-1960. J. Geophys. Res., 101, 3901-3920, https://doi.org/ 10.1029/95JD03237.

2001: Major optical depth perturbations to the stratosphere from volcanic eruptions: Stellar extinction period, 1961-1978. J. Geophys. Res., 106, 2993-3003, https://doi.org/10.1029/ 2000JD900652.

Taylor, K. E., R. J. Stouffer, and G. A. Meehl, 2012: An overview of CMIP5 and the experiment design. Bull. Amer. Meteor. Soc. 93, 485-498, https://doi.org/10.1175/BAMS-D-11-00094.1.

Tilmes, S., and Coauthors, 2013: The hydrological impact of geoengineering in the Geoengineering Model Intercomparison Project (GeoMIP). J. Geophys. Res. Atmos., 118, 11036 11 058, https://doi.org/10.1002/jgrd.50868.

Trenberth, K. E., and A. Dai, 2007: Effects of Mount Pinatubo volcanic eruption on the hydrological cycle as an analog of geoengineering. Geophys. Res. Lett., 34, L15702, https:// doi.org/10.1029/2007GL030524.

Wang, B., J. Liu, H.-J. Kim, P. J. Webster, and S.-Y. Yim, 2012: Recent change of the global monsoon precipitation
(1979-2008). Climate Dyn., 39, 1123-1135, https://doi.org/ 10.1007/s00382-011-1266-z.

Wegmann, M., S. Brönnimann, J. Bhend, J. Franke, D. Folini, M. Wild, and J. Luterbacher, 2014: Volcanic influence on European summer precipitation through monsoons: Possible causes for "years without summer." J. Climate, 27, 3683-3691, https://doi.org/10.1175/JCLI-D-13-00524.1.

Wielicki, B. A., and Coauthors, 2002: Evidence for large decadal variability in the tropical mean radiative energy budget. Science, 295, 841-844, https://doi.org/10.1126/science.1065837.

Willett, K. M., N. P. Gillett, P. D. Jones, and P. W. Thorne, 2007: Attribution of observed surface humidity changes to human influence. Nature, 449, 710-712, https://doi.org/10.1038/ nature 06207.

Zambri, B., and A. Robock, 2016: Winter warming and summer monsoon reduction after volcanic eruptions in Coupled Model Intercomparison Project 5 (CMIP5) simulations. Geophys. Res. Lett., 43, 10920-10928, https://doi.org/10.1002/ 2016GL070460. 